\title{
Are infant feeding options that are recommended for mothers with HIV acceptable, feasible, affordable, sustainable and safe? Pregnant women's perspectives
}

\author{
Marina Manuela de Paoli ${ }^{1, *}$, Rachel Manongi ${ }^{2}$ and Knut-Inge Klepp ${ }^{1}$ \\ ${ }^{1}$ Institute for Nutrition Research, University of Oslo, PO Box 1046 Blindern, 0316 Oslo, Norway: ${ }^{2}$ Kilimanjaro \\ Christian Medical College, Community Health Department, PO Box 3010, Moshi, Tanzania
}

Submitted 19 August 2003: Accepted 17 December 2003

\begin{abstract}
Objective: To investigate pregnant women's views on infant feeding options recommended for HIV-infected women.

Design: A structured interview survey complemented with focus group discussions. Setting: Antenatal clinics in Moshi urban and rural districts of Tanzania.

Subjects: Five hundred pregnant women participated in the interview survey and 46 pregnant women participated in six focus group discussions.

Results: Participating women reported that they would change to an alternative infant feeding method if they were found to be HIV-infected and were advised to do so. Cow's milk was regarded as the most feasible infant feeding method for local HIVinfected mothers. Infant feeding formula was regarded as too costly, but if recommended by health workers and distributed free of charge, the majority of the women (82\%) were confident that they would then choose this option. In the focus group discussions, women were less optimistic and expressed great concern for the social consequences of not breast-feeding. The safety of exclusive breast-feeding was questioned. Less common infant feeding methods, such as expressed heat-treated breast milk and wet-nursing, were not regarded as viable options. Several social barriers to replacement feeding were identified in the focus group discussions, including possible lack of support from partner and potential negative reactions from the community.

Conclusion: Future research on infant feeding options should include the broader cultural context and the psychological stress that HIV-infected women face when choosing infant feeding methods.
\end{abstract}

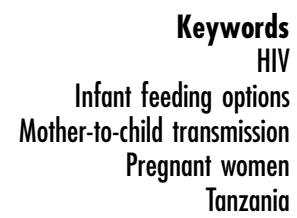

Transmission of HIV through breast-feeding is a pressing public health problem in resource-poor settings ${ }^{1-3}$. The current Joint United Nations Programme on HIV/AIDS (UNAIDS)/World Health Organization (WHO)/United Nations Children's Fund (UNICEF) guidelines recommend that HIV-infected mothers should avoid all breast-feeding in settings where replacement feeding is acceptable, feasible, affordable, sustainable and safe ${ }^{4}$. If the available replacement feeding methods do not meet these criteria, exclusive breast-feeding is recommended during the first months of life $\mathrm{e}^{4}$. Other recommended infant feeding methods are expressed heat-treated breast milk and wet-nursing ${ }^{5}$. Although these guidelines acknowledge the difficulties of choice, they do not articulate how these choices or decisions should be made other than that HIV-infected women should receive specific guidance through counselling. Making the decision to breast-feed or practise replacement feeding involves complex issues that are difficult to assess and that can be highly variable over time ${ }^{6}$.

The advantages of breast-feeding for infant health are well recognised ${ }^{7}$. However, the information required to determine local policy and inform HIV-infected women is for the most part not yet available. Studies investigating whether the use of other replacement foods in addition to infant feeding formula are feasible and/or locally acceptable and whether they can be practised safely are largely lacking ${ }^{8}$. It has been suggested that, in resourcepoor settings, the avoidance of breast-feeding is unlikely to be acceptable, feasible, affordable or safe, and that breast-feeding will remain the most appropriate choice for most women ${ }^{8}$. Studies have demonstrated that rates of exclusive breast-feeding can be increased ${ }^{9-11}$, but it remains a rare practice in sub-Saharan Africa ${ }^{12,13}$.

The aim of this study was to investigate pregnant women's views on infant feeding options recommended 
for HIV-infected mothers. Specifically, we explored their perceptions of the benefits and drawbacks associated with each feeding option, including their confidence (selfefficacy) that they would be able to use an alternative infant feeding method.

\section{Methods and subjects}

This study was conducted between June and September of 1999 at nine government antenatal clinics in the Moshi urban and rural districts of the Kilimanjaro region of Tanzania. At the time of the study, no PMTCT (prevention of mother-to-child transmission of HIV (MTCT)) activities were operational in the community, and infant feeding formula was not provided free of charge or at subsidised cost to HIV-infected mothers. However, at some antenatal clinics, healthcare workers had recently started to include the risk of MTCT during pregnancy as part of their health messages. In 1999, Tanzania was working with UNICEF to support the initiation of a PMTCT programme, and the national guidelines were in line with the existing international guidelines on infant feeding and HIV.

A total of 503 pregnant women were approached and asked to participate in an interview during their antenatal visits. Of those approached, 500 participated (99.4\%). The participants were recruited in collaboration with the healthcare staff at the participating clinics. The staff had been thoroughly informed about the purpose of the study and instructed to invite women of different ages, parity, marital status, ethnicity, socio-economic status and religion. The study employed a purposive sampling design in which pregnant women were invited to participate when they came to one of the clinics included in the study.

Five trained nurses from Kilimanjaro Christian Medical College (KCMC), the regional referral hospital, conducted the interviews. In order to secure reliable and valid data, the five interviewers were given a 10-day intensive training course on interviewing techniques prior to the study. We were, however, not able to measure the inter-observer variation, as only one interviewer interviewed each woman.

\section{Focus group discussions}

Six focus group discussions (FGDs) were conducted with a total of 46 pregnant women. These women were recruited from the selected antenatal clinics. A skilled fieldworker served as the moderator and the main author served as an assistant moderator. The moderator was responsible for conducting the discussions according to the interview guide and keeping the conversation flowing. The discussions were conducted in Swahili, the national language. In this paper, information obtained from the FGDs has been used to complement and validate the survey results.

The interview guide covered a broad range of topics and was flexible so as to encompass questions on emerging relevant themes, which were included in subsequent discussions for the validation and clarification of unexpected findings.

During our fieldwork, a South African study reported that infants who were exclusively breast-fed had no higher risk of HIV infection than those who were never breastfed $^{14}$. Thus, we included exclusive breast-feeding as a topic in the FGDs.

\section{Survey instrument}

A pre-tested, structured questionnaire administered in Swahili was used and consisted of four parts: (1) demographic factors; (2) previous infant feeding experience and knowledge of breast-feeding issues; (3) HIV/AIDS and MTCT-related knowledge; and (4) perceptions regarding the recommendations in the revised UNAIDS/WHO/UNICEF guidelines (after a brief orientation $)^{5,15}$. The women were not tested for HIV and their actual HIV status was not inquired about. The results concerning previous infant feeding practices and expressed willingness to accept voluntary counselling and HIV testing have been presented elsewhere ${ }^{12,16}$.

The structured survey was guided by the conceptual framework of Social Cognitive Theory ${ }^{17}$. In this model, self-efficacy is an important factor influencing behavioural change, as it reflects the confidence a person feels about performing a particular activity, including confidence in overcoming the barriers to performing that activity ${ }^{18}$. Selfefficacy has successfully been used in two studies where maternal confidence was found to be a strong predictor of breast-feeding behaviour ${ }^{19,20}$.

Self-efficacy was assessed by asking women a series of questions measured on a scale ranging from 0 to 4 . Sum scores were created by adding the relevant items for each construct and dividing by the number of items included. Thus, for all sum scores, 0 indicates low efficacy and 4 indicates high efficacy. A total of six self-efficacy (SE) scales were developed assessing women's confidence about the different infant feeding methods for HIVpositive women (see Appendix).

\section{Sociodemographics}

The sociodemographic factors included were age, level of education, marital status, employment status, religion, parity and clinic attendance. Primary education I included women who had 1-4 years of schooling and primary education II included women with 5-7 years of schooling. Perceived nutrition security in the household ${ }^{21,22}$ and the standard of housing were used as secondary measures of socio-economic status. Nutrition security is a composite variable and was measured by asking the participants to describe the food situation in their household and evaluate their own health and their children's health (Cronbach's $\alpha=0.65$ ). The standard of housing variable was dichotomised as modern (cement house with an iron 
roof) versus traditional (mud or mud-brick house with an iron or thatched roof).

\section{Analysis}

All statistical analyses were carried out using SPSS-PC, version 11.0 (SPSS, Inc., Chicago, IL, USA). These analyses included internal consistency and reliability analysis using Cronbach's $\alpha$, Pearson's correlation and analysis of variance.

The FGDs were tape-recorded, transcribed and coded using the qualitative program, Open Code ${ }^{23}$. During the analysis, data were examined for themes concerning infant feeding in order to determine which infant feeding methods were perceived as acceptable, feasible, affordable, sustainable and safe. We also sought to reveal women's expectations of the outcome of not breast-feeding.

\section{Etbical clearance}

Research and ethical clearances were obtained from the Tanzania National AIDS Control Program, the Tanzania Commission for Science and Technology, the Tanzania Food and Nutrition Centre, the KCMC Ethical Committee and the Norwegian Committee for Medical Research Ethics. No names or data that could identify individual participants were collected, and the data were treated in a strictly confidential manner.

\section{Results}

The sociodemographic characteristics of the sample are presented in Table 1. There was a high degree of internal consistency for all six self-efficacy constructs, with Cronbach's $\alpha$ ranging from 0.67 to 0.86 . The intercorrelations of the constructs were low to moderate (range from 0 to 0.41 ), with only two above 0.40 .

Breast milk was highly valued by the 500 surveyed women, and all but one of them completely agreed that breast milk is the best way to feed a child (disregarding HIV). By comparison, 21\% of the women completely agreed that cow's milk was the best method and $8 \%$ completely agreed that infant feeding formula was best (more than one feeding method could be designated as 'best').

In the FGDs, breast-feeding also appeared to be regarded as the best infant feeding method and the preferred choice of all women regardless of their economic resources. Some women expressed concern that a child may not grow healthy without its mother's milk.

\section{Replacement feeding}

The surveyed women reported confidence in being able to practise an alternative feeding strategy if they were HIVinfected (SE I). The highest self-efficacy was among women who were older, had more education, were married, had permanently employed husbands, lived in a
Table 1 Sociodemographic characteristics of the sample $(n=500)$

\begin{tabular}{lr}
\hline & Total sample, \\
& $n(\%)$ \\
\hline Age (years) & \\
$16-20$ & $124(24.8)$ \\
$21-25$ & $155(31.0)$ \\
$26-30$ & $140(28.0)$ \\
$31-44$ & $81(16.2)$ \\
Education & \\
Primary education I & $51(10.2)$ \\
Primary education II & $366(73.2)$ \\
Secondary/higher education & $83(16.6)$ \\
Marital status & \\
Single/separated/widow & $72(14.4)$ \\
Married/cohabiting & $428(85.6)$ \\
Employment & \\
Farmer & $208(41.6)$ \\
Housewife/student/unemployed & $131(26.2)$ \\
Petty trader/day-worker/other work & $122(24.4)$ \\
Permanent employment & $39(7.8)$ \\
Husband's employment & \\
Farmer & $90(21.1)$ \\
Student/petty trader/unemployed/ & $186(43.6)$ \\
day-worker/other work & \\
Permanent employment & $151(35.4)$ \\
Religion & \\
Christian & $379(75.8)$ \\
Non-Christian & $121(24.2)$ \\
Parity & \\
1 & $167(33.4)$ \\
2 & $122(24.4)$ \\
3 & $84(16.8)$ \\
$4+$ & $127(25.4)$ \\
House & \\
Traditional & $210(42.1)$ \\
Modern & $289(57.9)$ \\
Nutrition security & $84(17.8)$ \\
Low & $135(28.7)$ \\
Low-average & $121(25.7)$ \\
Average-high & $131(27.8)$ \\
High & \\
\hline & \\
\hline &
\end{tabular}

modern house and had a high perceived nutrition security (Table 2). The self-efficacy regarding the safety and sustainability of the preparation of an alternative feeding method (SE VI) was also high. The highest self-efficacy was among women who had more education, were permanently employed, were primiparous, lived in a modern house and had a high perceived nutrition security (Table 2).

In the FGDs, the women were less optimistic and expressed great concern for the social consequences of not breast-feeding. There was a high perceived risk of stigmatisation:

'You will just have problems if you tell people that you are HIV-infected. It is better to keep quiet. I think that people in my community would not want to have anything more to do with me if they knew that I was infected. I will just tell them that I have decided to feed my child on other milk.'

Women in the FGDs often told us that they would readily respond with a white lie to any curious question as to why they were not breast-feeding: 
Table 2 Self-efficacy (mean values) among pregnant women by sociodemographic variables (one-way analysis of variance)

\begin{tabular}{|c|c|c|c|c|c|c|c|}
\hline & \multirow[b]{2}{*}{$n$} & \multicolumn{6}{|c|}{ Self-efficacy scale } \\
\hline & & SE I & SE II & SE III & SE IV & SE V & SE VI \\
\hline \multicolumn{8}{|l|}{ Overall $†$} \\
\hline Mean (standard deviation) & 500 & $3.0(0.8)$ & $1.5(0.9)$ & $2.5(1.0)$ & $0.9(0.6)$ & $1.2(0.8)$ & $3.2(0.5)$ \\
\hline \multicolumn{8}{|l|}{ Age (years) } \\
\hline $16-20$ & 124 & $2.9^{*}$ & 1.6 & 2.5 & 1.0 & 1.2 & 3.2 \\
\hline $21-25$ & 155 & 3.0 & 1.4 & 2.5 & 0.9 & 1.2 & 3.2 \\
\hline $26-30$ & 140 & 3.2 & 1.5 & 2.5 & 0.8 & 1.1 & 3.3 \\
\hline $31-44$ & 181 & 3.0 & 1.3 & 2.4 & 0.9 & 1.2 & 3.2 \\
\hline \multicolumn{8}{|l|}{ Education } \\
\hline Primary education I & 51 & $2.7^{\star \star}$ & $1.1^{\star \star \star}$ & $2.0^{\star \star \star}$ & 0.9 & 1.0 & $2.9^{\star \star \star}$ \\
\hline Primary education II & 366 & 3.0 & 1.4 & 2.5 & 0.9 & 1.2 & 3.2 \\
\hline Secondary/higher education & 83 & 3.2 & 1.8 & 2.9 & 0.9 & 1.2 & 3.4 \\
\hline \multicolumn{8}{|l|}{ Marital status } \\
\hline Single/separated/widow & 72 & $2.8^{\star \star}$ & 1.4 & $2.2^{*}$ & 1.0 & 1.1 & 3.2 \\
\hline Married/cohabiting & 428 & 3.0 & 1.5 & 2.5 & 0.9 & 1.2 & 3.2 \\
\hline \multicolumn{8}{|l|}{ Employment } \\
\hline Farmer & 208 & 2.9 & $1.3^{\star \star \star}$ & 2.4 & 0.9 & 1.2 & $3.2^{*}$ \\
\hline Housewife/student/unemployed & 131 & 3.1 & 1.6 & 2.5 & 1.0 & 1.1 & 3.2 \\
\hline Petty trader/day-worker/other work & 122 & 3.2 & 1.6 & 2.6 & 0.9 & 1.2 & 3.3 \\
\hline Permanent employment & 39 & 3.1 & 2.0 & 2.8 & 0.9 & 1.2 & 3.4 \\
\hline \multicolumn{8}{|l|}{ Husband's employment } \\
\hline Farmer & 90 & $2.8^{\star \star}$ & $1.2^{\star \star}$ & $2.2^{\star \star}$ & $0.8^{*}$ & 1.2 & 3.2 \\
\hline Student/petty trader/unemployed/day-worker/other work & 186 & 3.1 & 1.6 & 2.7 & 1.0 & 1.2 & 3.2 \\
\hline Permanent employment & 151 & 3.1 & 1.6 & 2.5 & 0.8 & 1.2 & 3.3 \\
\hline \multicolumn{8}{|l|}{ Parity } \\
\hline Primiparous & 167 & 3.0 & $1.7^{\star *}$ & 2.5 & 1.0 & 1.2 & $3.3^{\star}$ \\
\hline Multiparous & 333 & 3.0 & 1.4 & 2.5 & 0.9 & 1.2 & 3.2 \\
\hline \multicolumn{8}{|l|}{ Clinic attendance } \\
\hline Rural & 249 & 3.0 & $1.4^{\star}$ & 2.4 & 0.9 & 1.1 & 3.2 \\
\hline Urban & 251 & 3.0 & 1.6 & 2.5 & 0.9 & 1.2 & 3.2 \\
\hline \multicolumn{8}{|l|}{ House } \\
\hline Traditional & 210 & $2.9^{*}$ & $1.3^{\star \star \star}$ & $2.3^{\star \star}$ & 0.9 & 1.2 & $3.2^{*}$ \\
\hline Modern & 289 & 3.1 & 1.6 & 2.6 & 0.9 & 1.2 & 3.3 \\
\hline \multicolumn{8}{|l|}{ Nutrition security } \\
\hline Low & 84 & $2.7^{\star \star \star}$ & $0.9^{\star \star \star}$ & $1.8^{\star \star \star}$ & 0.9 & 1.2 & $3.0^{\star \star}$ \\
\hline Low-average & 135 & 3.0 & 1.6 & 2.4 & 1.0 & 1.3 & 3.2 \\
\hline Average-high & 121 & 3.1 & 1.5 & 2.8 & 0.9 & 1.1 & 3.2 \\
\hline High & 131 & 3.2 & 1.6 & 2.7 & 0.9 & 1.2 & 3.3 \\
\hline
\end{tabular}

† Mean and standard deviation for the whole sample.

${ }^{\star}, P<0.05 ;{ }^{* *}, P<0.01 ;{ }^{* * *}, P<0.001$.

'If someone asks me why I am not breast-feeding I will frankly answer that I have got no milk.'

'So up to now you have been breast-feeding your children, but how come this time you are not? You have to tell them some lies which involve the doctor's advice...'

At the same time the FGD participants felt strongly that, if HIV-infected, they would give priority to not infecting their unborn child. The survival of the child of an HIVpositive mother was a strong incentive when mothers discussed the acceptability of alternative feeding methods:

'I will not care if people talk about me (for not breast-feeding). What people say does not matter; my main concern is to protect my child from getting HIV. I may even tell them that I am infected. So what? We are all going to die...'

FGD participants also emphasised the importance of involving fathers in the choice of feeding method. The subordinate position of women was often mentioned as a barrier:
'We always fear our husbands, and feel somehow insecure to discuss things with them. This makes the spread of HIV/AIDS even more serious. We are not in a position to negotiate safe sex nor safely disclose our HIV status, even though it really is necessary to be open and tell each other the truth.'

In the Kilimanjaro region, especially in rural areas, there is a traditional maternity leave, where the supposedly nursing mother is cared for by her mother-in-law during the first three months after childbirth. The mother-in-law is a highly respected person, and the women frequently questioned how a mother could oppose her and refuse to breast-feed, if she was not willing to disclose her HIV status.

It was stated in the FGDs that families would have to weigh the risk of infecting their infants against the necessity of spending more money on replacement feeding:

'They will do their best to find a solution so that the HIVpositive mother will not have to breast-feed her infant. Although it will be difficult to provide the child with other 
milk, they will manage. They will soon realise that, if this mother is HIV-infected, she will die, and if she continues to breast-feed her child, it too will die, and they will have to bury two people. They will take their economic situation into consideration, but they will conclude that it is better if only one person dies. I believe that, after they have been counselled, some families will find a way to buy milk so that the mother will not have to breast-feed and the child may not die.'

The FGD women also stated that they would normally follow the advice given by a health worker:

'Women like us follow the advice of a doctor or a nurse. When you have a fever and are prescribed a certain medicine to be taken two tablets in the morning, two at noon, and two in the afternoon, you have to follow the prescription. I believe that the same is true for the infant feeding advice given; women will do what they are told.'

\section{Infant feeding formula}

Among the surveyed mothers, 5.0\% responded that infant feeding formula was their most feasible option and 1.8\% said it was generally the most feasible option for HIVinfected women in this region. Infant feeding formula generally scored low as an affordable and sustainable choice (SE II). The highest self-efficacy was among women who had higher education, were in permanent employment, had husbands who were not farmers, were primiparous, attended an urban clinic, lived in a modern house or had a high perceived nutrition security (Table 2). If the formula were to be distributed free of charge, however, women's self-efficacy increased (mean 3.2; standard deviation 1.0), with $82.4 \%$ of the women responding that they were confident that they would then choose formula.

In the FGDs, only a few women said that they would be able to use formula, and most women suggested that only the more privileged women could afford it.

\section{Modified cow's milk}

The surveyed women's views regarding the best infant feeding method for HIV-positive mothers did not vary with sociodemographic factors. Among the surveyed women, 95.8\% regarded cow's milk as their most feasible option, and an equally high percentage (97.4\%) regarded it as the most feasible option for HIV-infected mothers in this area. The self-efficacy regarding the affordability and sustainability of cow's milk was also the highest of all infant feeding methods examined (SE III). The highest selfefficacy was among women who had more education, were married, had husbands who were not farmers, lived in a modern house or had a high perceived nutrition security (Table 2).

Cow's milk was regarded as the most feasible and acceptable replacement feeding method in the FGDs as well. It was perceived to be available and affordable (if child health was given priority), and it was commonly used to supplement the infant diet. However, some women expressed concern that it would not be affordable in rural settings:

I think most of us will not have enough money. In our village not even half the mothers would be able to afford cow's milk to feed their children. It is really not possible!'

Cow's milk was usually sold by private persons to whom the women had some kind of relationship. They could therefore pay for it on a monthly basis, which was seen as an advantage. Some women said they would cope each day with the problem:

I will try to buy cow's milk every day. If I do not have enough money, I will sell some onions, tomatoes, bananas ... anything, until I have enough money to buy milk.

\section{Wet-nursing and expressed beat-treated breast milk} Less common infant feeding methods, such as wet-nursing (SE IV) and expressed heat-treated breast milk (SE V), were neither well accepted by most surveyed women nor regarded as feasible options (Table 2). Wet-nursing was also regarded as the least acceptable option in the FGDs.

'Oh, this is not easy! People will start asking the wet-nurse why she is breast-feeding so and so's child.'

'So every time...[laughter]. . your child is crying, you will have to run to the neighbour?'

'What do you have to do in return for this wet-nurse so that she will agree to breast-feed your child?'

'The breast milk of another mother is not safe. Even if the wetnurse was HIV-tested today, she might become infected while she is wet-nursing, and she will then infect the child.'

Although expressing and heat-treating breast milk is a promising approach for making breast-feeding safer, it involves two new practices that have to be introduced and sustained on a daily basis, and which may arouse suspicion among neighbours and family. Thus this method was regarded as neither feasible nor acceptable by FGD and survey women.

\section{Exclusive breast-feeding}

Exclusive breast-feeding practised for a short period followed by abrupt weaning was perceived as contradictory to the FGD women's newly acquired awareness that breast milk can transfer the virus. This option was neither commonly practised nor easily understood, and it was regarded with scepticism as a safe replacement feeding method for HIV-infected women.

'Can a child really be fed on breast milk only, with no addition of water, for the first six months?'

'What kind of breasts can produce enough milk for the first six months if this child is not supposed to be fed anything else? 
However, if a healthcare worker advised the mother to practise exclusive breast-feeding, most women in the FGDs believed that this advice would be adhered to:

I would not like to infect my child. So, if I am told that by practising exclusive breast-feeding I may not infect my child, I will follow the health worker's advice. Most women will understand and follow this advice, especially if a doctor tells them.'

\section{Discussion}

In the Kilimanjaro region, there is a strong breast-feeding tradition and prolonged partial breast-feeding is widely practised $^{12,24,25}$. Strongly held beliefs about the benefits of breast-feeding for the baby and perceived social norms in favour of breast-feeding may induce deep tensions in HIVinfected mothers. We found in an earlier study that the decision whether or not to breast-feed was regarded as complicated and a very difficult choice for HIV-infected women $^{26}$.

Despite this strong breast-feeding culture, women had high self-efficacy with regard to practising an alternative feeding method, especially using cow's milk. Although the intention to use cow's milk was strong among the surveyed women, it is likely that an intention to practise some kind of replacement feeding will be more optimistic than the mother's actual behaviour. We have reported previously on the breast-feeding duration of the last liveborn child and the intended breast-feeding duration of the next expected child of the same pregnant women. We found that their intention to breast-feed far exceeded their previous breast-feeding practice ${ }^{12}$.

The more affluent women were the most confident that they could practise replacement feeding that entailed monetary cost. The self-efficacy of infant feeding formula was also high if distributed free of charge. In the FGDs, however, women were less optimistic. Women's low decision-making power, poverty and social stigma were regarded as major barriers to practising a replacement feeding method. Furthermore, several studies have reported difficulties for women to practise some kind of replacement feeding ${ }^{26-28}$.

The fact that the highest self-efficacy for infant feeding formula was reported among primiparous women may reflect their inexperience with breast-feeding and their inflated expectations about the use of infant feeding formula. It could also indicate a change, where the average breast-feeding duration may gradually decline in Tanzania in the coming years. In a previous article ${ }^{12}$ we reported that young urban women (unmarried, not farmers, higher education, of low parity) reported a shorter intention to breast-feed than did older rural women. This finding is further supported by an anthropological study undertaken in a neighbouring region, reporting that young childless women to a large degree perceived their breasts in terms of their attractiveness rather than their function ${ }^{29}$. This contrasts with the traditional perception of breasts, which gives greater emphasis to their functional attribute, i.e. producing milk for the infant.

The safety of exclusive breast-feeding was questioned by most women in the FGDs, and it remains a challenge to motivate and enable HIV-infected mothers to practise it. If exclusive breast-feeding is to be a viable option, the early introduction of fluids other than breast milk $^{12,30}$ will have to be challenged. Further research is needed to understand why mothers continue the practice of partial breastfeeding, and to determine whether this practice can be easily changed in sub-Saharan Africa.

There seemed to be a consensus that neither wetnursing nor expressed heat-treated breast milk was an acceptable, feasible, sustainable or socially safe alternative. It is possible to teach women how to hand-express breast milk, but heat-treating it to a specific temperature requires skill and proper facilities. Especially in rural areas, it is questionable whether this practice could be sustained. Wet-nursing is not a common practice in this region. It would require disclosure of the mother's HIV status to the wet-nurse and HIV-testing of the wet-nurse herself.

As illustrated by the FGDs, Tanzanians usually rely on health workers' advice, especially doctors. The fact that many women do not question this advice, partly because they trust them and partly because of authoritarian attitudes held by many health workers $^{26,31,32}$, is a challenge for counsellors, and informed decision-making is seriously compromised. Given the complexity of the information to be conveyed, informed decision-making also entails educational challenges for the counsellors. It has been reported that those counselling HIV-infected women do not always have adequate knowledge of the risks and benefits of each feeding method and of HIV transmission in general ${ }^{26,33,34}$. It is of utmost importance that HIV-infected mothers be provided with correct information and accessible mechanisms of support.

The self-efficacy regarding the safety and sustainability of preparing replacement feeding was high (especially among the more educated and affluent women). However, it is questionable whether the women understood these questions or were over-optimistic and unaware of how difficult it is to prepare replacement food in a safe and hygienic way. This further suggests the importance of training health workers in preparation methods and hygienic practices so that they are able to give HIV-infected women appropriate advice.

It seems likely that women of unknown HIV status will have thought less about what being HIV-infected actually entails and what decisions have to be made. We found, however, that these women's choice of infant feeding method and perceived barriers differed little from HIVinfected women's reported choices and dilemmas ${ }^{26,27,33}$. HIV/AIDS is such an overwhelming health problem in 
sub-Saharan Africa that pregnant women seem to have no difficulty relating to the scenario of being HIV-infected. Furthermore, since counselling is usually provided late in pregnancy, HIV-infected women often have to make decisions on infant feeding as soon as they learn their HIV status. Therefore, we think that the views reported in this study are similar to the initial reactions of mothers to whom a positive HIV-test has been abruptly conveyed. The use of different research methods gives further support to our findings.

A limitation of this study is that the women were recruited and interviewed in antenatal clinics and not at random. Recruiting through the antenatal clinics is assumed to give a representative sample, as the coverage of first-time antenatal clinic attendance is as high as $76 \%$ in Tanzania $^{35}$. Although the women were not randomly selected, we believe that the instructions given to the healthcare workers secured a wide selection of pregnant women representative for the whole population. Furthermore, the sociodemographic characteristics of the group were comparable with those of the local urban Tanzanian population, apart from our sample reporting a higher educational attainment (16.6\% vs. 3.4\% having completed secondary or higher education $)^{36}$. Another limitation of our study is that we were not able to estimate the interobserver variation, as only one interviewer interviewed each woman. We have not been able to identify any methodological studies investigating inter-observer variation in a sub-Saharan setting, and such studies are clearly called for.

The internal consistency was high for all included selfefficacy scales. Although there seemed to be overoptimism within the group concerning preparation methods, the fact that the more educated/affluent women were the most optimistic strengthens the internal validity. The self-efficacy scales developed in this study seem to be useful for assessing women's perceptions of replacement feeding, but did not encompass the perceived social barriers, which became apparent in the FGDs. We recommend that these scales be further developed, tested and not least compared with actual practice.

\section{Conclusion}

Despite a local culture strongly supportive of breastfeeding, women participating in this study reported that they would change to an alternative infant feeding method if they were found to be HIV-infected and were advised to do so. Cow's milk was regarded as affordable, acceptable, sustainable and feasible by women in this community. However, several social barriers to replacement feeding were identified in the FGDs, including possible lack of support from husbands and potential negative reactions from the community.

Research on programmatic implementations of infant feeding options in the context of HIV must include the broader cultural context and the psychological stress that HIV-infected women face in their choice of infant feeding method. It must also explore acceptable ways of involving the male partner. Since women in resource-poor settings frequently appeared have no other choice but breastfeeding, and recommended infant feeding methods are not regarded as viable, it seems important to give more attention to developing strategies for promoting exclusive breast-feeding, proper breast-feeding practices and ways of keeping HIV-infected women healthy.

\section{Acknowledgements}

We would like to thank the pregnant women who willingly participated in this study. This project was funded primarily by the Norwegian Research Council, with supplementary funding from the Throne Holst Foundation (University of Oslo) and Norwegian Save the Children. The project was conducted as part of a Health System Research Project supported by the Norwegian Council of Universities' Programme for Development Research and Education and facilitated by the collaborating institutions: Muhimbili University College of Health Sciences, Kilimanjaro Christian Medical College, Centre for Educational Development in Health, Arusha in Tanzania and the Universities of Oslo and Bergen, Norway.

\section{References}

1 Kuhn L, Stein S. Infant survival, HIV infection, and feeding alternatives in less developed countries. American Journal of Public Health 1997; 87(6): 926-31.

2 Humphrey J, Iliff P. Is breast not best? Bringing balance to a complex issue. SAfAiDS News 2001; 9(3): 18-20.

3 Coutsoudis A, Rollins NC. Breastfeeding and HIV transmission: the jury is still out. Journal of Pediatric Gastoenterology and Nutrition 2003; 36: 434-42.

4 World Health Organization (WHO). New Data on the Prevention of Mother-to-child Transmission of HIV and Their Policy Implications. Conclusions and Recommendations. Technical Consultation of the United Nations Population Fund (UNFPA)/United Nations Children's Fund (UNICEF)/ WHO/Joint United Nations Programme on HIV/AIDS (UNAIDS) Inter-Agency Task Team on Mother-to-Child Transmission of HIV. Geneva: WHO, 2000.

5 Joint United Nations Programme on HIV/AIDS (UNAIDS)/ World Health Organization (WHO)/United Nations Children's Fund (UNICEF). HIV and Infant Feeding. A Guide for Health Care Managers and Supervisors. Geneva: WHO, 1998.

6 Piwoz EG, Ross J, Humphrey J. Human immunodeficiency virus-transmission during breastfeeding: knowledge, gaps and challenges for the future. In: Pickering LK, Morrow AL, Ruiz-Palacios GM, Schanler RJ, eds. Protecting Infants through Human Milk: Advancing the Scientific Evidence Base. New York: Kluwer Academic/Plenum Publishers, 2004.

7 WHO Collaborative Study Team on the Role of Breastfeeding on the Prevention of Infant Mortality. Effect of breastfeeding on infant and child mortality due to infectious diseases in less developed countries: a pooled analysis. Lancet 2000; 355: 451-5.

8 Nicoll A, Newell M-L, Peckham C, Luo C, Savage F. Infant 
feeding and HIV-1 infection. AIDS 2000; 14(Suppl. 3): S57-74.

9 Haider R, Ashworth A, Kabir I, Huttly SRA. Effect of community-based peer counsellors on exclusive breastfeeding practices in Dhaka, Bangladesh: a randomised controlled trial. Lancet 2000; 356: 1643-7.

10 Morrow AL, Guerrero ML, Shults J, Calva JC, Lutter C, Bravo J, et al. Efficacy of home-based peer counselling to promote exclusive breastfeeding: a randomised controlled trial Lancet 1999; 353: 1226-31.

11 Kramer MS, Chalmers B, Hodnet ED, Sevkovskaya Z, Dzikovich I, Shapiro S, et al. Promotion of breastfeeding intervention trial (PROBIT) - a randomized trial in the Republic of Belarus. Journal of the American Medical Association 2001; 285(4): 413-20.

12 De Paoli M, Manongi R, Helsing E, Klepp K-I. Exclusive breastfeeding in the era of AIDS. Journal of Human Lactation 2001; 17(4): 313-20.

13 Bland RM, Rollins NC, Coutsoudis A, Coovadia HM Breastfeeding practices in an area of high HIV prevalence in rural South Africa. Acta Paediatrica 2002; 91(6): 704-11.

14 Coutsoudis A, Pillay K, Spooner E, Kuhn L, Coovadia HM Influence of infant feeding patterns on early mother-to-child transmission of HIV-1 in Durban, South Africa: a prospective cohort study. Lancet 1999; 354: 471-6.

15 Joint United Nations Programme on HIV/AIDS (UNAIDS)/ World Health Organization (WHO)/United Nations Children's Fund (UNICEF). HIV and Infant Feeding. Guidelines for Decision-makers. Geneva: WHO, 1998.

16 De Paoli MM, Manongi R, Klepp K-I. Factors influencing acceptability of voluntary counselling and HIV-testing among pregnant women in northern Tanzania. AIDS Care 2004; in press

17 Baranowski T, Perry CL, Parcel GS. How individuals, environments, and health behaviour interact. Social Cognitive Theory. In: Glanz K, Lewis FM, Rimer BK, eds. Health Behavior and Health Education. Theory, Research, and Practice, 3rd ed. San Francisco, CA: Jossey-Bass, 2002; $165-74$.

18 Bandura A. Self-efficacy - The Exercise of Control. New York: WH Freeman, 1997.

19 Dennis C-L. Theoretical underpinnings of breastfeeding confidence: a self-efficacy framework. Journal of Human Lactation 1999; 15(3): 195-201.

20 Torres MM, Torres D, Parilla Rodriguez AM, Dennis C-L. Translation and validation of the breastfeeding self-efficacy scale into Spanish: data from a Puerto Rican population. Journal of Human Lactation 2003; 19(1): 35-42.

21 Jonsson U. Nutrition and the Convention on the Rights of the Child. Food Policy 1996; 21(1): 41-57.

22 Oshaug A, Eide WB, Eide A. Human rights: a normative basis for food and nutrition relevant policies. Food Policy 1994; 19: $491-516$.
23 Winkvist A, Dahlgren L, Emmelin M Open Code Qualitative Program [online], 2003. Available from: http://www.umu. se/phmed/epidemi/forskning/open_code.html

24 Bureau of Statistics (Tanzania)/Macro International Inc. Tanzania Demographic and Health Survey 1996. Calverton, MD: Bureau of Statistics and Macro International, 1997.

25 Agnarsson I, Mpello A, Gunnlaugsson G, Hofvander Y, Greiner T. Infant feeding practices during the first six months of life in a rural area in Tanzania. East African Medical Journal 2001; 78(1): 6-10.

26 De Paoli MM, Manongi R, Klepp K-I. Counsellors' perspectives on antenatal HIV testing and infant feeding dilemmas facing women with HIV in northern Tanzania. Reproductive Health Matters 2002; 10(20): 144-56.

27 Kuhn L, Mathews C, Fransman D, Dikweni L, Hussey G. Child feeding practices of HIV-positive mothers in Cape Town, South Africa. AIDS 1999; 13(1): 144-6.

28 Omari AA, Luo C, Kankasa C, Bhat GJ, Bunn J. Infant-feeding practices of mothers of known HIV-status in Lusaka, Zambia. Health Policy and Planning 2002; 18(2): 156-62.

29 Muryn C. Perceptions of Food, Health and Body Ideal in the context of Urbanisation and Western Influence. A Study focussing on Young Women in Arusha, Tanzania. Oslo: Institute for Nutrition Research, University of Oslo, 2001.

30 Shirima R, Greiner T, Kylberg E, Gebre-Medhin M. Exclusive breast-feeding is rarely practised in rural and urban Morogoro, Tanzania. Public Health Nutrition 2001; 4(2): $147-54$.

31 Seidel G, Sewpaul V, Dano B. Experiences of breastfeeding and vulnerability among a group of HIV-positive women in Durban, South Africa. Health Policy and Planning 2000; 15(1): $24-33$

32 Seidel G. Reconceptualising issues around HIV and breastfeeding advice: finding from KwaZulu-Natal, South Africa. Review of African Political Economy 2000; 27(86): 501-18.

33 Chopra M, Sengwana J, Schaay N, Sanders D. Effect of a mother-to-child HIV prevention programme on infant feeding and caring practices in South Africa. South African Medical Journal 2002; 92(4): 298-302.

34 Programme Review Team PMTCT Advisory Group and Infant Study Group. Evaluation of a pilot programme and a follow-up study of infant feeding practices during the scaledup programme in Botswana. Evaluation and Programme Planning 2002; 25: 421-31.

35 Ministry of Health. The Reproductive and Child Health Report [Taarifa ya huduma ya afya ya uzazi na mtoto]. Kilimanjaro, Tanzania: Ministry of Health, 2002 [in Kiswahili]

36 Bureau of Statistics (Tanzania)/Macro International Inc. Tanzania Demographic Health Survey. Calverton, MD: Bureau of Statistics and Macro International, 1999. 


\section{Appendix - Questions included in the self-efficacy constructs}

Self-efficacy I: Acceptability of alternative feeding methods for HIV-positive women (Cronbach's $\alpha=0.67$ )

If you were tested HIV-positive, and were advised not to breast-feed due to the risk of infecting your new-born child:

Q1. How confident are you that you would follow this advice?

Q2. How confident are you that you would find an alternative feeding strategy?

Self-efficacy II: Affordability and sustainability of providing infant feeding formula (Cronbach's $\alpha=0.78$ )

Q1. If you were HIV-positive, how confident are you that you could afford to buy enough milk-powder for 1 month?

Q2. If you were HIV-positive, how confident are you that you could afford to buy enough infant feeding formula for 4-6 months?

Q3. If you could not afford to buy enough infant feeding formula to feed your baby, how confident are you that you could get economic support from someone?

Single question about providing infant feeding formula free of charge

If you were HIV-positive and infant feeding formula was offered free of charge to all HIV-positive mothers, how confident are you that you would then choose not to breast-feed?

Self-efficacy III: Affordability and sustainability of providing cow's milk (Cronbach's $\alpha=0.86$ )

Q1. If you were HIV-positive, how confident are you that you could afford to buy enough cow's milk for 1 month?

Q2. If you were HIV-positive, how confident are you that you could afford to buy enough cow's milk for 4-6 months?

Self-efficacy IV: Acceptability and feasibility of wet-nursing and finding a suitable wet-nurse (Cronbach's $\alpha=0.67$ )

Q1. Is it acceptable to let a child be breast-fed by someone else than the mother?

Q2. Would you agree to let someone else breast-feed your child if you were advised not to breast-feed?

Q3. If you were HIV-positive, and advised not to breast-feed but to use a wet-nurse, how confident are you that you could find someone who could serve as a wet-nurse?

Self-efficacy V: Sustainability of expressed heat-treated breast milk (Cronbach's $\alpha=0.79$ )

Q1. How confident are you that you would be able to express enough milk, heat it and then feed your baby for the first month?

Q2. How confident are you that you would be able to express enough milk, heat it and then feed it to your baby for 4-6 months?

Self-efficacy VI: Safety and sustainability of preparing replacement feeding (Cronbach's $\alpha=0.78$ )

Q1. How confident are you that you would be able to (read or) understand and to follow the instructions for preparing infant feeding formula properly?

Q2. How confident are you (that if you were instructed) you would manage to prepare cow's milk properly?

Q3. How confident are you that you will have access to clean water on a regular basis to enable you to safely prepare the milk?

Q4. How confident are you that you have access to enough fuel to enable you to cook water/milk in order to feed your child?

Q5. How confident are you that you would manage to prepare the milk in a hygienic way? 